\title{
Perspectivas sobre os processos \\ transmidiáticos e o Grupo de Pesquisa Games, Educação, Mídia e Sentido (GEMS)
}

\section{Perspectives on transmedia processes and the Games, Education, Media and Sense Research Group (GEMS)}

\author{
Perspectivas sobre procesos transmedia y el \\ Grupo de Investigación sobre Juegos, \\ Educación, Medios y Sentido (GEMS)
}

\author{
Aline Cristina Camargo \\ Universidade Estadual Paulista Júlio de Mesquita Filho - SP - Brasil \\ ORCID: https://orcid.org/0000-0001-8854-1810 \\ Endereço currículo Plataforma Lattes: http://lattes.cnpq.br/7340783113175141 \\ E-mail: alinecamargo20@gmail.com \\ Antonio Francisco Magnoni \\ Universidade Estadual Paulista Júlio de Mesquita Filho - SP - Brasil \\ ORCID: https://orcid.org/0000-0002-6495-8045 \\ Endereço currículo Plataforma Lattes: http://lattes.cnpq.br/5884461869811166 \\ E-mail: afmagnoni@unesp.br \\ Luciane de Fátima Giroto Rosa \\ Universidade Estadual Paulista Júlio de Mesquita Filho - SP - Brasil \\ ORCID: https://orcid.org/0000-0001-7787-2294 \\ E-mail: lucianegiroto@hotmail.com \\ Elaine Regiane Damaceno Ribeiro \\ Universidade Estadual Paulista Júlio de Mesquita Filho - SP - Brasil \\ E-mail: elainedamaceno@gmail.com \\ Janaina Leite de Azevedo \\ Universidade Estadual Paulista Júlio de Mesquita Filho - SP - Brasil \\ ORCID: https://orcid.org/0000-0002-9774-9215 \\ Endereço currículo Plataforma Lattes: http://lattes.cnpq.br/0445800627984962 \\ E-mail: janaina.azevedo@gmail.com \\ Sillas Carlos dos Santos \\ Universidade Estadual Paulista Júlio de Mesquita Filho - SP - Brasil \\ Endereço currículo Plataforma Lattes: http://lattes.cnpq.br/4514821874498320 \\ E-mail: sillascarlos@gmail.com
}


CAMARGO, MAGNONI, ROSA, RIBEIRO, AZEVEDO, SANTOS, LEITE, MIRANDA, 2020

\author{
Wellington César Martins Leite \\ Universidade Estadual Paulista Júlio de Mesquita Filho - SP - Brasil \\ ORCID: https://orcid.org/0000-0003-3675-4384 \\ Endereço currículo Plataforma Lattes: http://lattes.cnpq.br/2037713942936648 \\ E-mail: wellington_cml@hotmail.com \\ Giovani Vieira Miranda \\ Universidade Estadual Paulista Júlio de Mesquita Filho - SP - Brasil \\ ORCID: http://orcid.org/0000-0001-5708-4151 \\ Endereço currículo Plataforma Lattes: http://lattes.cnpq.br/3249812382402062 \\ E-mail: giovani.vieira.miranda@gmail.com
}

Resumo: Este artigo trata-se de uma proposta ensaística que tem como objetivo realizar um breve relato histórico do surgimento dos meios de comunicação e do contexto atual da organização do trabalho, da força convergente possibilitada pela informática e de seus desdobramentos socioculturais para, então, apresentar o relato de apresentação do grupo de pesquisa GEMS (Games, Educação, Mídia e Sentido), que tem os estudos transmídia como mote transversal em suas pesquisas. Neste sentido, são apresentados os objetivos de cada um dos subgrupos que formam o GEMS, bem como são discutidas suas relações com os processos transmidiáticos. As informações aqui descritas foram obtidas a partir de reuniões realizadas entre os integrantes dos subgrupos. Formado por profissionais das mais diversas áreas, os estudos empreendidos no grupo seguem a linha de Gestão Midiática e Tecnológica do programa de pós-graduação em Mídia e Tecnologia da Faculdade de Arquitetura, Artes e Comunicação (FAAC) UNESP de Bauru/SP.

Palavras-chave: Transmídia. GEMS. Gestão Midiática e Tecnológica.

\begin{abstract}
This article is an essay proposal that aims to provide a brief historical of the emergence of the media and the current context of work organization, the converging force made possible by information technology and its socio-cultural developments, so that, presentation report of the research group GEMS (Games, Education, Media and Sense), which has transmedia studies as a transversal theme in its research. In this sense, the objectives of each of the subgroups that form the GEMS are presented, as well as their relations with the transmedia processes are discussed. The information described here was obtained from meetings held among members of the subgroups. Formed by professionals from the most diverse areas, the studies undertaken in the group follow the line of Media and Technological Management of the graduate program in Media and Technology of the Faculty of Architecture, Arts and Communication (FAAC) UNESP of Bauru/SP.
\end{abstract}

Keywords: Transmedia. GEMS. Media and Technological Management.

Resumen: Este artículo es una propuesta de ensayo que tiene como objetivo proporcionar un breve relato histórico del surgimiento de los medios de comunicación y el contexto

DOI: http://doi.org/10.14393/par-v5n2-2020-56291 - Paradoxos, Uberlândia, v. 5, n. 2, p. 246-264, jul./dez. 2020 | 247 
actual de la organización del trabajo, la fuerza convergente que hacen posible las tecnologías de la información y sus desarrollos socioculturales, de manera que informe de presentación del grupo de investigación GEMS (Juegos, Educación, Medios y Sentido), que tiene los estudios transmedia como tema transversal en su investigación. En este sentido, se presentan los objetivos de cada uno de los subgrupos que forman el GEMS, así como se discuten sus relaciones con los procesos transmedia. La información aquí descrita se obtuvo de las reuniones realizadas entre los miembros de los subgrupos. Formado por profesionales de las más diversas áreas, los estudios realizados en el grupo siguen la línea de Gestión de Medios y Tecnología del programa de postgrado en Medios y Tecnología de la Facultad de Arquitectura, Artes y Comunicación (FAAC) UNESP de Bauru/SP.

Palabras-clave: Transmedia. GEMS. Gestión Mediática y Tecnológica.

\section{Introdução}

Abordar os objetivos e os campos de pesquisa do Grupo GEMS - Games, Educação, Mídia e Sentido - é uma tarefa um tanto ampla, em um momento histórico de radical convergência das tecnologias, das linguagens, dos usos e costumes individuais e coletivos, em que há constante expansão populacional e cultural da comunicação social. Podemos citar como principal objetivo do GEMS pesquisar os efeitos informativos e comunicativos, culturais e educativos, técnico-científicos, produtivos e econômicos, que são derivados do adiantado estado de desenvolvimento e da crescente disseminação e importância vital entre as sociedades contemporâneas, das tecnologias, dispositivos, programas, e redes informáticas.

Com o desenvolvimento e a consolidação da 'economia da informação' (SHAPIRO; VARIAN, 2003), que sustenta a presumida e tão propagandeada 'sociedade do conhecimento' (AMARAL, 2006), a produção derivada do trabalho simbólico adquiriu condição de mercadoria virtual estratégica para a sustentação do novo capitalismo online. Evidência disso são os milhões de trabalhadores precários utilizados pelos conglomerados capitalistas "globalizados", principalmente naqueles setores com atividades mais "qualificadas e intelectualizadas", podem ser originários de qualquer continente ou país, e muitos deles derivam das parcelas escolarizadas da "classe" média, que possuem formação técnica ou superior.

Outro fator muito influente para a atual configuração dos novos sistemas e negócios DOI: http://doi.org/10.14393/par-v5n2-2020-56291 - Paradoxos, Uberlândia, v. 5, n. 2, p. 246-264, jul./dez. 2020 | 248 


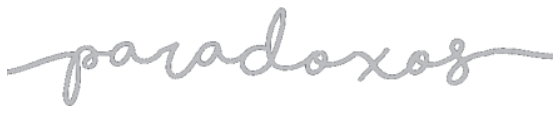

Perspectivas sobre os processos transmidiáticos

e o Grupo de Pesquisa Games, Educação,

Mídia e Sentido (GEMS)

CAMARGO, MAGNONI, ROSA, RIBEIRO, AZEVEDO, SANTOS, LEITE, MIRANDA, 2020

de comunicação é a dinâmica evolutiva internacional de novas plataformas e de ferramentas digitais. A contínua multiplicação e a popularização de dispositivos de comunicação disseminam tecnologias, aplicativos e linguagens midiáticas que criam novos hábitos sociais de recebimento e de reenvio de informação, além de novas formas de consumo de entretenimento e oferecem mais serviços, enquanto ampliam os mercados e os espaços de divulgação e comercialização de uma infinidade de bens materiais e simbólicos.

\section{As revoluções modernas não foram somente industriais, mas também culturais}

As tão mencionadas "revoluções ou ciclos industriais", cujos efeitos foram pesquisados até a exaustão por diversas áreas dos conhecimentos contemporâneos, também precisam ser estudados mais minuciosamente pelos cientistas da Comunicação Social. Afinal, os mencionados fenômenos não produziram somente mudanças objetivas em contextos materiais, econômicos e políticos presentes nas diversas configurações cotidianas das sociedades e dos estados-nações daquela época.

Assim, as principais matrizes sociais predominantes na atualidade derivaram diretamente dos processos científicos e tecnológicos, e das "invenções" que ajudaram a consolidar as contínuas transformações produtivas, vivenciais, políticas e culturais. Foram mudanças contínuas e de diversas naturezas e efeitos que também caracterizariam, por mais de um século, os legados da Modernidade urbana-industrial, dita repetidamente como ocorrência de um fenômeno exclusivamente ocidental.

No entremeio daquelas novas mudanças na produção material fabril que alteravam as possibilidades e os modos de consumo coletivo de bens materiais, também foram registradas significativas inovações técnicas e uma multiplicação de investimentos destinados à produção e difusão de informações de interesse público, que foram convertidas em linguagens e em outros tipos de produtos midiáticos de natureza simbólica, que eram impressos e distribuídos pelos diversos ramos de atividades gráfico-editoriais.

\section{A escolarização regular atende os setores produtivos e amplia o mundo da cultura e do consumo mediado}

A alfabetização massiva, sobretudo a partir da criação dos sistemas escolares públicos, provocou aumento contínuo das populações leitoras, enquanto o assalariamento DOI: http://doi.org/10.14393/par-v5n2-2020-56291 - Paradoxos, Uberlândia, v. 5, n. 2, p. 246-264, jul./dez. 2020 | 249 


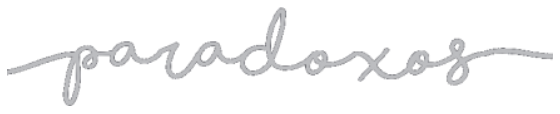

Perspectivas sobre os processos transmidiáticos

e o Grupo de Pesquisa Games, Educação,

Mídia e Sentido (GEMS)

CAMARGO, MAGNONI, ROSA, RIBEIRO, AZEVEDO, SANTOS, LEITE, MIRANDA, 2020

fabril trouxe renda estável para parcelas crescentes de trabalhadores, fator que contribuiu para multiplicar também os tipos de publicações e o público consumidor delas.

Durante a primeira revolução industrial, cujo epicentro inicial ocorreu no interior provinciano da Inglaterra, ainda predominavam as atividades gráficas derivadas daquelas técnicas primordiais criadas no século XV por Gutenberg que desenvolveu, na Europa, os primeiros processos de composição por tipos metálicos combináveis, além de iniciar o desenvolvimento de tintas e pigmentos gráficos e a impressão mecanizada das sequências de páginas inteiras de um livro ou um jornal. Naquela época pioneira houve muitas inovações, sobretudo, no campo publicitário e jornalístico.

Houve ciclos sucessivos de evoluções técnico-científicas, que criaram conhecimentos e condições objetivas para a mecanização gradual do trabalho nos ambientes industriais e para a expansão das redes de meios públicos de transporte de carga e passageiros, como os navios e trens a vapor, e também de comunicação de massa, com o aprimoramento da imprensa diária sustentada pela publicidade, além do desenvolvimento das tecnologias de transmissão de informações em tempo real, como o telégrafo e o telefone.

Ao longo do século XX, houve contínua multiplicação e popularização de veículos de comunicação, que com a abrangência crescente de suas linguagens e dispositivos específicos, foram disseminando tecnologias, linguagens e criando novos hábitos sociais de consumo de informação, de publicidade e entretenimento, além de contribuírem para a multiplicação de serviços, de mercados nacionais e regionais, de nichos culturais e ideológicos.

\section{A automatização informatizada e o desenvolvimento da comunicação, da produção e da cultura de redes e dispositivos informacionais}

Cada nova tecnologia poderá alterar a qualidade do conteúdo, o formato e a definição da mensagem emitida, poderá ampliar as possibilidades de interação com o público, etc. Ou seja, as mudanças tecnológicas incidem diretamente no resultado econômico, na ação profissional, nos sentidos da linguagem e da estética dos meios. E, sobretudo, repercutem na maneira do público receber, interpretar e interagir com as mensagens recebidas.

O contexto de mundialização das empresas e dos sistemas financeiros capitalistas, hoje denominado globalização, começou a ser desenvolvido também nos anos 1970 com a "robotização" industrial informatizada e a instalação de sistemas digitais de DOI: http://doi.org/10.14393/par-v5n2-2020-56291 - Paradoxos, Uberlândia, v. 5, n. 2, p. 246-264, jul./dez. 2020 | 250 


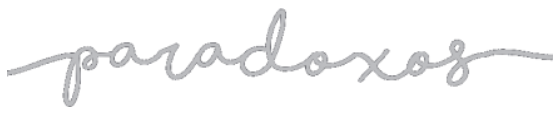

telecomunicações com alcance mundial.

Entretanto, as transformações provocadas pela inserção crescente da informática nos ambientes industriais tiveram efeitos radicais, significativos e abrangentes, mas que ainda permaneceram restritas aos ambientes fabris, embora a automatização computadorizada (ou a robotização fabril) tenha impulsionado e agudizado muito mais a secular evolução competitiva (ou destruição criadora) inerente às relações produtivas e econômicas do capitalismo industrial.

\section{O desenvolvimento do ciberespaço e a "globalização" digital}

Foi a partir dos anos 1990 que os ciclos de digitalização das tecnologias eletroeletrônicas saíram dos ambientes produtivos para se espraiarem por todos os espaços e atividades sociais. Nenhum ciclo tecnológico anterior teve tão grande e rápida expansão ou apresentou níveis tão profundos de aperfeiçoamento tecnológico, como o havido com os sistemas de informação e de comunicação, a partir do desenvolvimento público e comercial da rede mundial de computadores.

Nos países capitalistas ocidentais, as tecnologias pioneiras da informática começaram a sair dos laboratórios universitários e governamentais de pesquisa nos EUA e Europa ainda no início dos anos 1950. As novas tecnologias derivadas da "eletrônica do silício" passaram a subsidiar com seus novos recursos e promissores recursos, os grandes conglomerados de fabricantes de artefatos da indústria bélica e de telecomunicações, setores industriais tecnocientíficos considerados como ultra estratégicos para o capitalismo internacional, durante as várias décadas de predomínio da "guerra fria".

Assim, desde o início dos anos 1960, em todo o mundo capitalista as infraestruturas de telecomunicações ganharam prioridade nos investimentos em pesquisa e desenvolvimento tecnológico, tanto dos governos nacionais e dos organismos públicos de financiamento, quanto das corporações privadas, que passaram a produzir ou importar e "nacionalizar" novos e custosos aparatos informatizados e estratégicos para serviços de transmissão e de recepção de dados, e também para monitoramento aeroespacial com fins civis e militares.

Os fenômenos conjunturais citados no artigo foram desencadeados pela informatização produtiva e comunicativa, que iria redesenhar partir da década de 1970, primeiramente nos países capitalistas desenvolvidos, o universo laboral- 


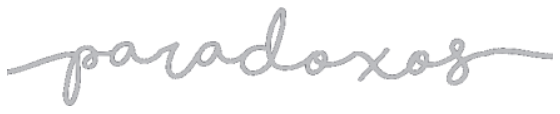

Perspectivas sobre os processos transmidiáticos

e o Grupo de Pesquisa Games, Educação,

Mídia e Sentido (GEMS)

CAMARGO, MAGNONI, ROSA, RIBEIRO, AZEVEDO, SANTOS, LEITE, MIRANDA, 2020

produtivo, financeiro, comercial, educativo e cultural, e também no campo de segurança e vigilância pública, interna e externa. Tais mudanças também desencadearam o desordenamento de economias pretensamente socialistas e altamente militarizadas, como a que havia na antiga União Soviética.

Hoje predomina a obsolescência profissional contínua provocada pela automatização da indústria e dos serviços, que suprime postos de trabalho enquanto aumenta seguidamente o volume produtivo, a qualidade das mercadorias e exige mais aprimoramento do trabalhador, para que ele possa realizar seu trabalho.

Neste contexto mundial tão desfavorável aos trabalhadores, a escolarização maciça, massiva e permanente é receitada como antídoto infalível para todas as mazelas sociais. A Educação é citada, exaustivamente, como única fonte geradora de oportunidades profissionais e de qualidades competitivas, indispensáveis para os indivíduos conseguirem êxito no mundo globalizado. Como a educação poderá acompanhar o ritmo do capitalismo pós-industrial, que está a substituir rapidamente a linha de montagem fordista, por redes mundiais de produção online?

O domínio da escrita inaugurou a comunicação não-presencial e permitiu que as informações rompessem as barreiras da distância e do tempo. As culturas antigas com registros escritos permitem ser transmitidas ou resgatadas plenamente pelas pesquisas históricas e arqueológicas, enquanto a existência das sociedades ágrafas pode ser testemunhada apenas pelos seus vestígios, que sempre receberão as interpretações contemporâneas.

Para Saviani (1993, p. 101), a sociedade aparece configurada em seu aspecto histórico pelo desenvolvimento, unitário ou conjunto, dos planos econômico, cultural, social e político. Para o autor, a análise concreta de qualquer um desses elementos, seja ela realizada de modo amplo ou num aspecto mais restrito, sempre se apresentará como "síntese de múltiplas determinações.” Ou seja: "cada aspecto mantém íntima relação com os demais, melhor dizendo, contém em si os demais, sintetiza-os, sintetizando a sociedade em seu conjunto." Convém destacar que Saviani, ao apontar a existência de uma relação dialética indivisível e extremamente complexa que move a historicidade humana, se aproxima metodologicamente de Morin, no sentido de apontar a necessidade

DOI: http://doi.org/10.14393/par-v5n2-2020-56291 - Paradoxos, Uberlândia, v. 5, n. 2, p. 246-264, jul./dez. 2020 | 252 
de elaboração de paradigmas complexos, integrais, histórico-críticos, para dar respostas objetivas para os problemas das sociedades contemporâneas. Castells nos adverte que:

[...] a tecnologia não determina a sociedade. Nem a sociedade escreve o curso da transformação tecnológica, uma vez que muitos fatores, inclusive criatividade e iniciativa empreendedora, intervêm no processo de descoberta científica, inovação tecnológica e aplicações sociais, de forma que o resultado final depende de um complexo padrão interativo. $\mathrm{Na}$ verdade, o dilema do determinismo tecnológico é, provavelmente, um problema infundado, dado que a tecnologia é a sociedade, e a sociedade não pode ser entendida ou representada sem suas ferramentas tecnológicas. (CASTELLS, 1999, p. 25).

Os valores burgueses também faziam distinção entre a cultura afeita às camadas sociais ligadas ao poder e ao capital, considerada pelos cânones das elites como cultura superior. Os novos ricos incultos buscaram a absorção rápida dessa "secular cultura aristocrática" para poderem se legitimar como nova classe dominante.

Para Ortiz (1988. P. 25), “o século XIX se caracteriza, portanto, pela emergência de duas esferas distintas: uma de circulação restrita, vinculada à literatura e às artes, outra de circulação ampliada, de caráter comercial. O público se encontra, desta forma, cindido em duas partes: de um lado uma minoria de especialistas, de outro, uma massa de consumidores".

A revolução burguesa tornou indissociável a relação indústria/produção/consumo. O consumo tornou-se combustível e característica imanente às sociedades modernas. A comunicação de massa e a indústria cultural derivam de outro episódio moderno, que é a urbanização populacional e a transformação das cidades industriais, em metrópoles. As cidades atuais se configuram como o exemplo mais bem elaborado das transformações do espaço, ocorridas desde o fim do século XVIII, um fenômeno histórico-geográfico que Milton Santos denominou de "momento da criação do meio técnico":

O meio natural era aquela fase da história na qual o homem escolhia da natureza aquilo que era fundamental ao exercício da vida e valorizava diferentemente essas condições naturais, as quais, sem grande modificação, constituíam a base material da existência do grupo. O fim do século XVIII e, sobretudo, o XIX vêem a mecanização do território [...]. Podemos dizer [...], que esse momento é o momento da criação do meio técnico, que substitui o meio natural. (SANTOS, 1996. P. 139).

O livro-texto passou a ser um instrumento definitivo para o ensino a partir da Revolução Industrial Inglesa e da Revolução Política Francesa. A educação pública e a liberdade de DOI: http://doi.org/10.14393/par-v5n2-2020-56291 - Paradoxos, Uberlândia, v. 5, n. 2, p. 246-264, jul./dez. 2020 | 253 


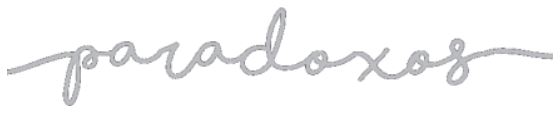

Perspectivas sobre os processos transmidiáticos

e o Grupo de Pesquisa Games, Educação,

Mídia e Sentido (GEMS)

CAMARGO, MAGNONI, ROSA, RIBEIRO, AZEVEDO, SANTOS, LEITE, MIRANDA, 2020

imprensa foram conquistas revolucionárias e democráticas celebradas pelos liberais e pelas massas populares. A alfabetização dos trabalhadores tornou-se o elemento indispensável ao desenvolvimento da produção capitalista. A nova sociedade industrial exigiu transporte e comunicações cada vez mais rápidos e maiores investimentos no desenvolvimento científico.

\section{O Grupo GEMS e suas relações com os processos transmidiáticos}

Há três subgrupos interdisciplinares que formam o grupo de pesquisa GEMS, a saber: 1 - Economia Criativa e Sistemas Produtivos, 2 - Mídia, Democracia e Novos Processos Informacionais e 3 - Linguagens, plataformas e gêneros dos Games e do Audiovisual Interativo. Seus integrantes possuem de 20 a 45 anos, do gênero masculino e feminino, residentes na cidade de Bauru e região. Participam desde alunos da graduação a discentes do doutorado, passando também por graduados e mestrandos. Alguns se dedicam de forma exclusiva aos estudos, sendo titulares de bolsas acadêmicas, outros estão inseridos no mercado de trabalho público e privado, sendo que alguns membros também atuam como docentes no ensino formal de nível superior e no ensino corporativo. As formações são variadas, existindo representantes da Comunicação Social: Jornalismo, Rádio e TV, bem como profissionais de Letras, Direito e Administração.

A heterogeneidade do grupo contribui de forma positiva para os estudos e pesquisas interdisciplinares levando à complementaridade do aprendizado e variada produção bibliográfica. No ano passado, o grupo realizou o I Seminário Nacional GEMS, um encontro de três dias, com mesas redondas, apresentação de trabalhos e rodada de protótipos no campus da FAAC, também na cidade de Bauru. O evento contou com profissionais que trabalham com as temáticas dos três subgrupos, estudantes, professores e profissionais do mercado interessados no tema.

Subgrupo 1 - Economia Criativa e Sistemas Produtivos

O campo de Economia Criativa e Sistemas Produtivos reúne membros do GEMS que pesquisam temas e autores, brasileiros e estrangeiros, da economia política da comunicação e cultura, notadamente, Luis Albornoz, Leonardo De Marchi, Felipe Trotta, entre outros. Evidenciam-se, basicamente, as desregulamentações que atacam os produtores de conteúdo (não os fornecedores de acesso): músicos, artistas, jornalistas,

DOI: http://doi.org/10.14393/par-v5n2-2020-56291 - Paradoxos, Uberlândia, v. 5, n. 2, p. 246-264, jul./dez. 2020 | 254 


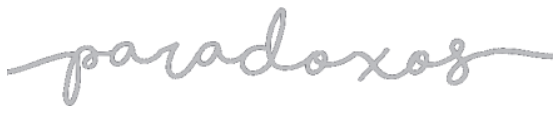

Perspectivas sobre os processos transmidiáticos

e o Grupo de Pesquisa Games, Educação,

Mídia e Sentido (GEMS)

CAMARGO, MAGNONI, ROSA, RIBEIRO, AZEVEDO, SANTOS, LEITE, MIRANDA, 2020

professores e quaisquer outros produtores de mensagens. Do pagamento por seus produtos e seus direitos de criação, até às facilidades de criação, registro, produção, veiculação e distribuição que, de forma ainda não monetizada, permitiu que muitas produções ganhassem viabilidade, sem garantir o sustento de seus autores.

Os processos transmidiáticos são uma vertente importante para algumas análises deste subgrupo tendo em vista que envolvem diversos aspectos de produção e disponibilização de conteúdo nos novos meios. Esses elementos podem verificados de forma crítica à luz do Direito de Propriedade Intelectual e suas regulamentações no âmbito das normas pátrias.

O professor norte-americano Henry Jenkis, em sua obra Cultura da Convergência (2008), pondera que a narrativa transmidiática, em especial, não pode ser traduzida numa simples técnica de contar as histórias por diversas mídias, mas como um processo complexo onde os elementos essenciais da trama podem ser distribuídos de forma organizada e planejada por diversos canais, com o objetivo de ser maximizada a experiência do leitor/expectador/audiência/estudante.

No que tange aos aspectos práticos, pode-se afirmar que a narrativa transmidiática traz uma importante inovação criativa que tem o poder de aumentar exponencialmente a interação do público com a história. A participação da audiência deixa de ser meramente receptiva para ser participativa valendo-se das inúmeras ferramentas das novas mídias, tais como games, histórias em quadrinhos, álbum de figurinhas, comunidades temáticas e narrativas ficcionais (fanfics) que complementam o enredo original.

Os atuais produtores audiovisuais deparam-se com o desafio de instrumentalizar as narrativas, antigas e atuais, com ferramentas digitais e recursos de transmidiação online e offline. O comportamento da nova audiência traduz uma geração que cresceu utilizando diversas plataformas midiáticas e aplicativos de informática e, portanto, se posiciona de forma cada vez mais ativa nos novos meios podendo consumir avidamente as mais variadas atrações audiovisuais e estilos de linguagens.

As estratégias de produção transmídia podem ser percebidas em vários desses processos. Na área de produção musical independente, por exemplo, as facilidades de registro audiovisual possibilitaram a exploração de diversos públicos em ambientes comunicacionais diversos. Nos smartphones, em programas de rádio e TVs locais e nos

DOI: http://doi.org/10.14393/par-v5n2-2020-56291 - Paradoxos, Uberlândia, v. 5, n. 2, p. 246-264, jul./dez. 2020 | 255 


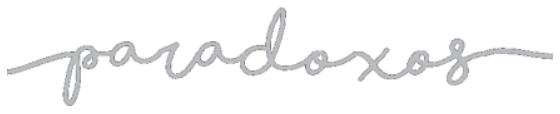

Perspectivas sobre os processos transmidiáticos

e o Grupo de Pesquisa Games, Educação,

Mídia e Sentido (GEMS)

CAMARGO, MAGNONI, ROSA, RIBEIRO, AZEVEDO, SANTOS, LEITE, MIRANDA, 2020

meios sociais, o conceito artístico desenvolvido em determinado projeto artístico e musical é levado ao público em forma de pílulas, convidando a conhecer o universo (SCOLARI, 2015) em criação que, se tudo der certo, gerará apresentações ao vivo (única forma garantida de geração de renda para esses trabalhadores).

Como nos diz Trotta, a "circulação em larga escala de sons musicais promoveu um intercâmbio antes inimaginável entre música, músicos e 'públicos' de locais afastados" (TROTTA, 2005, p.183). Dessa forma, a música "nunca" esteve tão acessível. Mas, como dissemos, também jamais foi tão difícil estabelecer o seu valor de troca, num mercado de bens simbólicos, que hoje é caracterizado pela superoferta de bens e serviços culturais (JANOTTI JR. et al; 2011, p. 24).

Se, por um lado, estamos ante uma complexa "paisagem cultural digital em processo de construção, do ponto de vista tecnológico", social e econômico (ALBORNOZ, 2011, p. 222), por outro, estamos em face de grande concentração econômica (TAPLIN, 2017). Mesmo que as ferramentas de registro, tratamento e veiculação estejam acessíveis a todos, como usálas de forma adequada e como viver do próprio trabalho nas redes digitais ainda não é tarefa fácil para muitos músicos e demais atores produtores de conteúdo.

Subgrupo 2 - Mídia, Democracia e Novos Processos Informacionais

A presença dos meios de comunicação de massa tem interferido na cultura coletiva e na formação da opinião pública desde a consolidação das sociedades urbanoindustriais. Os veículos massivos são os principais indutores do consumo de bens materiais e simbólicos e os principais disseminadores de informações jornalísticas entre as diversas camadas sociais. Assim, agem como canais especializados em difundir ou direcionar, ocasionalmente ou intencionalmente, os debates da vida pública.

Mesmo assim, grande parte dos estudos sobre a teoria democrática e a esfera pública ainda desconsidera o papel incisivo dos meios de comunicação nos espaços sociais contemporâneos, como se eles não existissem ou como se sua influência não fosse suficientemente determinante para explicar fenômenos sociais, como a conexão pública, a participação e o engajamento cívico dos cidadãos.

No contexto democrático em que vivemos, pressupõe-se que haja condições para que os cidadãos exerçam seus direitos individuais e coletivos, entre eles o de participação

DOI: http://doi.org/10.14393/par-v5n2-2020-56291 - Paradoxos, Uberlândia, v. 5, n. 2, p. 246-264, jul./dez. 2020 | 256 


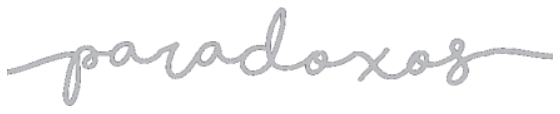

Perspectivas sobre os processos transmidiáticos

e o Grupo de Pesquisa Games, Educação,

Mídia e Sentido (GEMS)

CAMARGO, MAGNONI, ROSA, RIBEIRO, AZEVEDO, SANTOS, LEITE, MIRANDA, 2020

política. Com o desenvolvimento e a popularização da internet iniciaram-se as discussões em torno do potencial social, político e democrático da rede mundial de computadores. A internet oferece variedades crescentes de informações, reduz os custos de participação política e permite que os diferentes participantes possam se envolver no diálogo a partir da troca de e-mails, chats e grupos eletrônicos de discussão.

Entre a sociedade civil, já não há mais dúvidas de que as comunidades virtuais estão criando plataformas adicionais importantes para facilitar a participação cidadã na esfera pública do ciberespaço, seja de natureza política, profissional ou cultural.

Neste contexto, o subgrupo 2 tem como objetivo monitorar e avaliar os novos processos profissionais e amadores de produção e difusão de conteúdos digitalizados escritos, sonoros, pictóricos, fotográficos e audiovisuais em redes e dispositivos digitais no contexto das novas mídias, bem como identificar na atualidade brasileira as formas e objetivos de emissão-recepção-consumo de mensagens interpessoais e coletivas.

O contexto transmídia dá-se em um cenário em que o público brasileiro tem acesso a maior número de fontes e variedade de formas de acessar conteúdos de notícias a partir do uso da internet. A disseminação do uso da rede tem fornecido novas ferramentas, dispositivos e oportunidades para grupos minoritários e é uma fonte autônoma de notícias para as parcelas da população com acesso à internet domiciliar ou móvel. O acesso às redes amplia as possibilidades de uso frequente de canais midiáticos.

A comunicação mediada e massiva decorre da transmissão de mensagens de um emissor para um receptor, com a utilização de suportes físicos impressos, ou de sinais eletrônico (analógicos ou digitais), em ações regulares de publicação que geram fluxos informativos dotados de quatro elementos primordiais: fonte, destino, meio e mensagem (SCHIFFMAN; KANUK, 1991). A partir desse conceito torna-se inteligível a comunicação de massa, na qual ocorre a propagação simultânea de inúmeras informações em um mesmo período de tempo, e com alcance de grandes quantias de receptores.

Assim, Magnoni salienta:

O que caracteriza a comunicação em massa é a difusão de conteúdos informativos (jornalístico, de entretenimento, cultural-educativo etc.), que são produzidos com linguagens especializadas obtidas com processos profissionais de criação e edição, e distribuídas com a utilização de diversos tipos de tecnologias e de meios mais adequados para a publicação dirigida,

DOI: http://doi.org/10.14393/par-v5n2-2020-56291 - Paradoxos, Uberlândia, v. 5, n. 2, p. 246-264, jul./dez. 2020 | 257 
como os assinantes de jornais e revistas, quanto de maneira aberta e generalista, como ocorre com a radiodifusão. (MAGNONI, 2001, p. 112).

Para o referido autor, a secular imprensa foi pioneira da comunicação de massa e também do aprendizado não escolar, ao organizar desde o início do "renascimento europeu" sistemas informativos escritos e publicados com regularidade, a partir da produção mecanizada em escala, um modelo que antecipou as linhas de montagens industriais disseminadas a partir da segunda revolução industrial. Magnoni (2001) destaca ainda que a publicação periódica de jornais, revistas e almanaques sustentados por anúncios publicitários demarcou o início da "era da comunicação analógica" e também da segunda revolução industrial, período de ascensão definitiva do modelo econômico e social moderno, capitalista, e ocidental.

Nos períodos históricos mais contemporâneos, podemos apontar que o apogeu do desenvolvimento dos veículos analógicos que configuraram as atuais "indústrias culturais" e a criação de "opiniões públicas" nacionais e internacionais fortemente influenciadas pela comunicação e pela publicidade, que disseminaram e consolidaram as suas estratégias para estimular os valores ocidentais e o consumo de massa. Dos anos 1920 aos 50 houve o desenvolvimento técnico e comunicativo das emissoras de rádio, do cinema sonoro e das primeiras estações de televisão, veículos modernos bastante revolucionários, porque permitiram superar as barreiras geográficas enfrentadas pelos habitantes rurais e pelos povoamentos isolados, além de retirar numerosas parcelas de analfabetos da exclusão informativa e cultural.

A hegemonia obtida com a abrangência, a popularidade e a versatilidade comunicativa da radiodifusão sonora e audiovisual predominou durante o século 20 e só começaria a ser disputada a partir do final dos anos 1990 pelas redes fixas e móveis da internet.

O ciberespaço vem propiciando, desde então, o desenvolvimento de uma infinidade de aplicativos, de plataformas e dispositivos digitais, que passaram a ameaçar a liderança da "velha mídia analógica" ao conseguirem difundir pelos dispositivos digitais, mensagens para distintos grupos e nichos sociais, com alcance mundial, todas em tempo real ou diferido, sejam elas escritas, sonoras e audiovisuais.

Os versáteis recursos informáticos da internet, além de possibilitarem a comunicação multimidiática para todas as pessoas com conexão às suas redes, inauguraram a interatividade, que permite a distribuição de mensagens em fluxos 


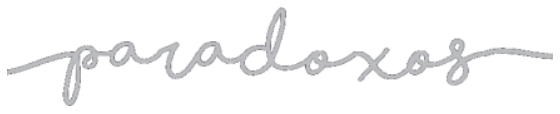

Perspectivas sobre os processos transmidiáticos

e o Grupo de Pesquisa Games, Educação,

Mídia e Sentido (GEMS)

CAMARGO, MAGNONI, ROSA, RIBEIRO, AZEVEDO, SANTOS, LEITE, MIRANDA, 2020

multilaterais. No âmbito da internet, houve potencialização progressiva do papel das mídias comerciais como influenciadoras do consumo de informação e de outros bens simbólicos, sejam jornalísticos, culturais e de entretenimento.

Na perspectiva de Jappe (2006), a comunicação e o consumo interligam-se em pelo menos três aspectos: o próprio consumo tem capacidade de comunicar-se diretamente com o público devido a sua linguagem fácil, que se aproveita da compulsão natural das pessoas para consumir bens materiais e simbólicos; a divulgação de produtos e de serviços nas diversas esferas coletivas passa a atuar como índices sociais; a importância comunicativa que a publicidade assumiu na era moderna, a partir do momento que a indústria simbólica conseguiu a transformar em mercadorias, a cultura e até os sentimentos coletivos.

Portanto, ao longo de todo o século 20 a produção e a inclusão crescente de novos significados entre as práticas coletivas de comunicação e de consumo foram consolidadas pela crescente mediação das diversas relações sociais cotidianas. As atuais sociedades de consumo procuram corresponder às demandas por mais velocidade e eficiência nas cadeias e fluxos de produção-distribuição-consumo, com o uso cada vez mais intenso de recursos de informação e comunicação, que são produzidos pela constante evolução das tecnologias digitais.

Nos tempos atuais, já não é possível ignorar as evidências de que a edificação industrial moderna está sendo substituída rapidamente pelas redes de silício da nova economia informacional. As promessas virtuais dessa globalização online têm exibido intenções ainda mais excludentes que aquelas utilizadas pelo capitalismo fabril. Ao deslocar a produção material do epicentro da economia e eleger a circulação e o consumo simbólico como o novo motor do capital produtivo, a regulação fabril flexível deu início à sua terceira revolução, que não é mais propriamente só industrial.

No campo da transmissão de dados e da oferta de recursos comunicativos, as redes ultra potentes de computadores e o desenvolvimento de outros equipamentos digitais permitiram criar canais multimidiáticos privados e públicos para as modalidades de comunicação contemporâneas, seja para a geração, distribuição e gestão de informações de natureza corporativa e privada, sejam os canais e redes sociais de comunicação interpessoal e coletiva.

Desde os primeiros anos da internet, se multiplicaram os endereços eletrônicos de portais convergentes de veículos dos vários ramos da comunicação 


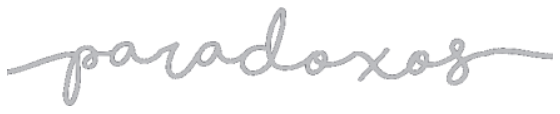

Perspectivas sobre os processos transmidiáticos

e o Grupo de Pesquisa Games, Educação,

Mídia e Sentido (GEMS)

CAMARGO, MAGNONI, ROSA, RIBEIRO, AZEVEDO, SANTOS, LEITE, MIRANDA, 2020

escrita, de rádio e televisão, alguns com divulgações parciais de seus conteúdos jornalísticos, outros com “espelhamento” digital integral dos conteúdos difundidos em seus canais analógicos. Também se multiplicaram os sites de serviços corporativos privados, de vendas ao consumidor e publicidade online.

As instituições do Estado, federais, estaduais e municipais, também intensificaram as suas publicações digitais em portais de transparência, de orientação aos usuários dos serviços públicos, de educação, cultura e cidadania. O desenvolvimento de uma infinidade de aplicativos e dispositivos de comunicação interpessoal contribuiu com uma relativa popularização da internet fixa e móvel, apesar de não ter prosperado no Brasil as propostas reivindicadas por pesquisadores e por movimentos sociais organizados, que defendiam a regulação democrática da radiodifusão brasileira, e também pleiteavam a criação governamental de um serviço nacional de conexão pública e de democratização para todos os cidadãos, do acesso digital com banda larga.

A internet permitiu a ampla digitalização das tecnologias articulada com a convergência dos conteúdos e das linguagens, recursos possíveis a partir do desenvolvimento de sistemas de compressão de arquivos de dados binários. É um fenômeno que derivou do aumento da capacidade de distribuição e difusão de informações, devido à articulação da informática com as telecomunicações, que produziu redes de transmissão, acesso e troca de informações pela internet e por outros dispositivos móveis que se conectam à rede mundial de computadores.

Com a tecnologia informática englobada no cotidiano dos jovens, as técnicas da comunicação disseminam-se cada vez mais entre a sociedade. Dessa forma, faz-se necessário desenvolver maneiras de produzir comunicação no contexto das mídias digitais, além da atualização das mídias tradicionais, de forma a criar um vínculo entre os produtores de informação e os atores sociais. Para Miguel (2002), a mídia é o principal mecanismo de divulgação dos pontos de vista e dos programas sociais e políticos. Apesar do cenário otimista acerca da utilização da internet, é preciso considerar que $58 \%$ dos brasileiros têm acesso à rede (BRASIL, 2016).

Subgrupo 3 - Linguagens, plataformas e gêneros dos Games e do Audiovisual Interativo O subgrupo 3 tem como objetos de pesquisa da linha a pesquisa, desenvolvimento

DOI: http://doi.org/10.14393/par-v5n2-2020-56291 - Paradoxos, Uberlândia, v. 5, n. 2, p. 246-264, jul./dez. 2020 | 260 


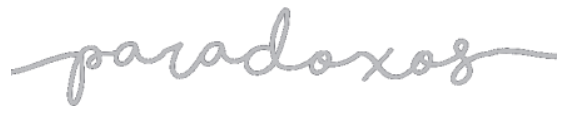

Perspectivas sobre os processos transmidiáticos

e o Grupo de Pesquisa Games, Educação,

Mídia e Sentido (GEMS)

CAMARGO, MAGNONI, ROSA, RIBEIRO, AZEVEDO, SANTOS, LEITE, MIRANDA, 2020

e experimentação de linguagens, gêneros e formatos para os games e o audiovisual interativo, especialmente em formatos transmidiáticos e gameficados.

Seus objetivos perpassam por analisar a multiplicação das narrativas e dos registros audiovisuais, interativos ou não, no ciberespaço, bem como as reconfigurações lúdicas, culturais e comunicativas no cotidiano midiatizado. Além de experimentar recursos e processos para produção de reportagens e documentários jornalísticos, de ficção audiovisual com edição individual ou seriada, de games para educação e entretenimento.

Atento às mudanças e especificidades das produções audiovisuais no atual contexto midiático, sejam elas séries, ficção radiofônica, filmes, games ou vídeos para a web, esse eixo de pesquisa comumente dialoga com a narrativa transmídia em sua forma mais conhecida, como foi popularizada por Jenkins em sua obra Cultura da Convergência: através da ficção.

Em meio às efervescências midiáticas, no que diz respeito a produtos audiovisuais como filmes e séries, destacam-se os hábitos de consumo de audiovisual por parte dos espectadores. Trespassando o simples ato de assistir, os fãs articulam-se tanto para recriarem suas próprias versões das histórias quanto para esmiuçarem cada detalhe das narrativas de seu interesse. Deste modo, cabe aos produtores audiovisuais elaborarem narrativas e obras audiovisuais que contemplem esta demanda. Para Mittel (2009) uma história capaz de aprofundar-se a ponto de sempre oferecer material diegético para os fãs pode ser chamada de perfurável. Uma narrativa perfurável encoraja os seus espectadores a engajarem nas ações propostas e a cavarem mais fundo em busca de mais detalhes da trama, enquanto examinam todo o material disponível na "superfície" da história para entender a sua complexidade (MITTEL, 2009).

Neste sentido, a narrativa transmídia contribui significativamente para a criação de universos e histórias perfuráveis. Ao pensar-se nestas narrativas como "histórias que se desenrolam em múltiplas plataformas de mídia, cada uma delas contribuindo de forma distinta para nossa compreensão do universo" (JENKINS, 2008, p. 384), percebe-se a capacidade destas de potencializar as possibilidades criativas para os produtores audiovisuais e também otimizar a experiência dos fãs com determinada produção audiovisual ao contribuir com a exploração da perfurabilidade da obra.

Uma narrativa audiovisual pode ser profunda o bastante para ser perfurável e também pode distribuir determinados elementos narrativos por diversos produtos 


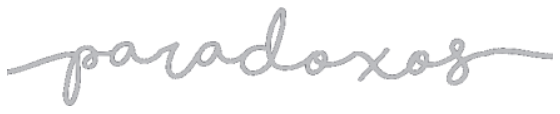

Perspectivas sobre os processos transmidiáticos

e o Grupo de Pesquisa Games, Educação,

Mídia e Sentido (GEMS)

CAMARGO, MAGNONI, ROSA, RIBEIRO, AZEVEDO, SANTOS, LEITE, MIRANDA, 2020

midiáticos. Espalhar o conteúdo de uma franquia por diferentes mídias ajudam de imediato, a agregar espectadores para um produto audiovisual de entretenimento, mas não significa que consigam assegurar um engajamento duradouro do público, mesmo daqueles fãs mais mobilizados. As narrativas perfuráveis envolvem menos pessoas, conforme fazem imersões mais profundas nas ações da trama. Por isto consomem mais tempo e dedicação de seus fãs, engajando-os na história contada, de modo mais duradouro (MITTEL, 2009). Deste modo, os fãs deparam-se com mais produtos de uma mesma franquia para realizarem sua prática de perfuração. Se outrora os esforços concentravam-se em uma única obra, hoje os mistérios e informações podem ser distribuídos por histórias derivadas da principal e distribuídas em diferentes plataformas de mídias e linguagem.

\section{Algumas Considerações}

A informação e a comunicação tornaram-se elementos complementares e essenciais para nutrir continuamente o núcleo binário da "nova economia digital", que adquiriu abrangência mundial, a partir do desenvolvimento da internet comercial. A cultura midiática criada no século passado legou uma extensa herança profissional, cultural, tecnológica e política, que ainda é utilizada por todos os meios de comunicação, sejam das "velhas" ou das "novas mídias".

Nos espaços virtuais da internet predomina um tempo sem fusos horários, que é determinado apenas pela velocidade e pela abrangência dos fluxos de informação. Nos ambientes informatizados e interligados pelas redes de computadores, as percepções de tempo e espaço locais também se tornaram globalizados. Na prática, hoje há o predomínio de um espaço-tempo virtual que dilata ou encolhe o seu alcance ou a duração conforme aumenta ou diminui a oferta de serviços de internet e a capacidade volumétrica da banda de tráfego, que também determina a velocidade de fluxo das redes e a melhor ou pior capacidade de acesso (ou de recepção) dos dispositivos.

Em uma era "pós-moderna e globalizada" a estupenda revolução digital da infocomunicação é apresentada como ícone absoluto da supremacia da técnica, da ciência e também da lógica concorrencial do mercado de bens de consumo material e simbólico, e também da extrema financeirização das economias nacionais, cada vez mais mundializadas.

DOI: http://doi.org/10.14393/par-v5n2-2020-56291 - Paradoxos, Uberlândia, v. 5, n. 2, p. 246-264, jul./dez. 2020 | 262 


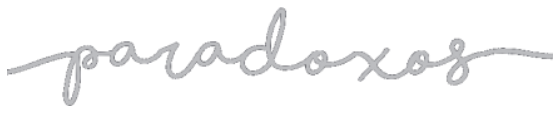

Perspectivas sobre os processos transmidiáticos

e o Grupo de Pesquisa Games, Educação,

Mídia e Sentido (GEMS)

CAMARGO, MAGNONI, ROSA, RIBEIRO, AZEVEDO, SANTOS, LEITE, MIRANDA, 2020

A consolidação da cultura ocidental percorreu um longo e multifacetado percurso histórico crivado de criações e manifestações abstratas e também de coisas tangíveis, como as técnicas e os conhecimentos práticos que orientavam a vida coletiva. O saber e o fazer estiveram presentes nos ambientes humanos, em qualquer época, sempre como elementos de ação ativa sobre pessoas e interveniente na própria realidade tecnológica e social. Portanto, não seria possível realizar uma apurada análise histórica se os eventos tecnológicos forem isolados do contexto geral do desenvolvimento da história ocidental.

Nos tempos atuais, educadores, pesquisadores e críticos midiáticos, na intenção de apontar os aspectos nocivos da comunicação de massa, que não são irrelevantes, têm se esmerado em destacar os aspectos negativos das indústrias culturais contemporâneas, que também não são poucos, e tampouco são inofensivos. As diversas possibilidades e virtudes da "cultura midiática" são subestimadas, ou então, são interpretadas de modo superficial, muito fragmentado e até descoladas das outras transformações modernas.

Urge alcançar toda a extensão e complexidade do objeto de pesquisa, que até agora não foi plenamente pesquisada e desvendada pelo universo educativoacadêmico. Nesse sentido, o estudo do transmídia pelo grupo GEMS tem se mostrado frutífero para todas as linhas de pesquisa permitindo a melhor compreensão do contexto atual e do futuro da cultura de convergência.

\section{Referências}

ALBORNOZ, L. A. Poder, Medios y Cultura - uma mirada crítica desde la economia política de la comunicación. Buenos Aires: Paidós, 2011.

AMARAL, R. (Org.). Sociedade do conhecimento: novas tecnologias, risco e liderança. Lages: Ed. Uniplac, 2006.

BRASIL. SECRETARIA DE COMUNICAÇÃO DA PRESIDÊNCIA DA REPÚBLICA. Pesquisa Brasileira de Mídia 2016: Hábitos de consumo de mídia pela população brasileira. Disponível em: 〈http://www.secom.gov.br/atuacao/pesquisa/listade-pesquisas-quantitativas-e-qualitativas-de-contratos-atuais/pesquisa-brasileira-demidia-pbm-2016.pdf/view >. Acesso em: 15 jul. 2020.

CASTELlS, M. A sociedade em rede. São Paulo: Paz e Terra, 1999. v. 1.

JANOTTI JR., J. S.; LIMA, T. R.; PIRES \& NOBRE, V. de A. (orgs). Dez Anos a Mil: Mídia e Música Popular Massiva em Tempos de Internet. Porto Alegre: Simplíssimo, 2011.

DOI: http://doi.org/10.14393/par-v5n2-2020-56291 - Paradoxos, Uberlândia, v. 5, n. 2, p. 246-264, jul./dez. 2020 | 263 


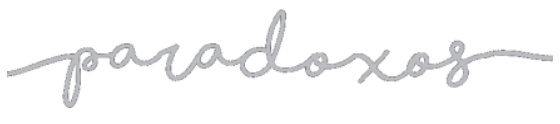

CAMARGO, MAGNONI, ROSA, RIBEIRO, AZEVEDO, SANTOS, LEITE, MIRANDA, 2020

JENKINS, H. Cultura da Convergência. São Paulo: Aleph, 2008.

JAPPE, A. As aventuras da mercadoria. Lisboa: Antígona, 2006.

MAGNONI, A. F. Primeiras aproximações sobre pedagogia dos multimeios para o ensino superior. 2001. Tese (Doutorado em Educação). Faculdade de Filosofia e Ciências, Universidade Estadual Paulista "Júlio de Mesquita Filho", Marília, 2001.

MIGUEL, L. Os meios de comunicação e a prática política, 2002. Disponível em: <http://www.scielo.br/pdf/ln/n55-56/a07n5556.pdf> Acesso em: 25 jul. 2020.

MITTELL, J. To Spread or to Drill? [s.1.]: Just TV, 2009. Disponível em:

<http://justtv.wordpress.com/.../02/25/to-spread-or-to-drill/>. Acesso em: 14 jul. 2020.

ORTIZ, R. A Moderna Tradição Brasileira. Brasiliense: São Paulo, 1988.

SANTOS, M. A natureza do espaço. São Paulo: Hucitec, 1996.

SAVIANI, D. Educação: Do senso comum à consciência filosófica. 11 ed. Campinas, SP: Autores Associados, 1993.

SCHIFFMAN, L. \& KANUK, L. Comportamento do Consumidor. 6. ed. Rio de Janeiro: Editora LTC, 2001.

SCOLARI, C. A. Ecología de los Medios - Entornos, Evoluciones e Interpretaciones. Barcelona: Editorial Gedisa, 2015.

SHAPIRO, C.; VARIAN, H. R. A economia da informação: como os princípios econômicos se aplicam à era da Internet. Elsevier Brasil, 2003.

TAPLIN, J. Move Fast and Break Things: How Facebook, Google, and Amazon Cornered Culture and Undermined Democracy. UK: Pan Macmillan, 2017.

TROTTA, F. Música e Mercado: a Força das Classificações, Contemporânea - Revista de Comunicação e Cultura, vol. 3. n. 2, 2005. Disponível em:

$<$ https://portalseer.ufba.br/index.php/contemporaneaposcom/article/view/3459>. Acesso em: 10 fev. 2020. DOI: https://doi.org/10.1017/s000768051800020x. 